\title{
The phenomenon of e-business networking: a critical review
}

\section{Sid Ghosh*}

The Business School

Bournemouth University, UK

Bournemouth House

19 Christchurch Road, Bournemouth, BH1 3LH, UK

E-mail: sghosh@bournemouth.ac.uk

*Corresponding author

\section{Martijn Bertisen}

E-Commerce Department

Dixons Group, UK

E-mail: martijn_bertisen@hotmail.com

\begin{abstract}
Today's fast-moving global business environment is forcing e-businesses to experiment with new forms of operational organisations. Collaborative strategic networking is essential in order to survive and succeed in the new economy emerging from the e-phenomenon. Networking, however, is a very advanced and complex form of cooperation, requiring careful consideration and critical evaluation of many e-business aspects. On the basis of the critical review of literature, this paper proposes a conceptual model for e-business networking consisting of 18 Critical Success Factors (CSF), integrated in four categories - in which strategic network performance represents the core, surrounded by network marketing, network design and network value delivery. This categorisation is important for practical applicability of the model. Based on the findings of a pilot survey among e-businesses, an importance index of CSF was developed, supporting the criticality of the success factors. This paper also provides specific suggestions for further development and improvement of the proposed model.
\end{abstract}

Keywords: e-business networking; critical success factors; importance index; sustainable competitive advantages.

Reference to this paper should be made as follows: Ghosh, S. and Bertisen, M. (xxxx) 'The phenomenon of e-business networking: a critical review', Int. J. Information Technology and Management, Vol. X, No. Y, pp.000-000.

Biographical notes: Sid Ghosh is a Senior Lecturer in Operations Management in the Business School of Bournemouth University, UK. He has published his research in international journals, such as The International Journal of Project Management, Business Process Management Journal, The International Journal of Quality and Reliability Management, and others. He has been awarded a best paper prize at the British Academy of Management Conference held at the Said Business School, Oxford University in the year 2005. His name will appear in the 2006-2007 edition of Marquis Who's Who in Science and Engineering. 
Martijn Bertisen is an Assistant Manager with the E-commerce Department in Dixons Group, UK. He has completed his Master's degree in International Business Management with distinction. His Master's dissertation has been awarded the best project prize in the Business School of Bournemouth University.

\section{Introduction}

The concept of e-phenomenon is rapidly expanding and impacting on businesses more than ever before. The development of business models for conducting e-business is not simply about the adoption of new technologies, but also challenges the existing business models (Vassilopoulou et al., 2002). Most of the existing business models in other business contexts are also represented within the e-phenomenon context (Rowley, 2002, p.14); however Castells (2000) has argued that the 'new economy' is fundamentally different from the traditional models. He suggests that success now depends on the effective use of knowledge, the implementation of global/worldwide concepts and the creation of networks among several actors, as well as interaction between various existing business networks. Walters and Buchanan (2001) highlight that the concepts vary and companies are seeking to become networked, virtual, horizontal or project based. However, all these concepts express a need at the dawn of a new century to develop flatter, more flexible and intelligent forms of organising (Walters and Buchanan, 2001).

Networks are often defined as very complex in nature, or as Cook and Emerson (1984, p.3) suggest, networks are "sets of connected exchange relationships between actors controlling business activities". In light of the topic of this study, the most suitable explanation found in literature is suggested by Koza and Lewin (2000, p.21), defining a network as "a form of collaboration among multiple companies in which, typically, the network members are each specialised, bringing a unique value-adding resource to the network such as market access or skills".

Collaborative networks in e-business are new. Hack (2001) argues that few case studies, methodologies and tools are available to ensure successful implementations of relationship and business practices via the internet. Networking is a very advanced and complex form of cooperation, which means that unless the interests and goals are compatible or modified to fit each other, the alliance will ultimately run into problems and disagreements. This may ultimately jeopardise any future cooperation and subsequently damage company reputation and customer satisfaction (Hinterhuber and Hirsch, 1998). Nevertheless, literature identifies the need for effective strategies for networking. McCullough and Johnston (2001) find that the potential benefits are increasing rapidly as traditional hierarchies transform into the ecosystems of e-business.

Through the creation of networks, e-businesses will gain access to each other's resources and activities and cooperate in offering an improved customer service quality. This in return will additionally make the network connections stronger and support the development of competitive advantages not only over each direct competitor, but also within the industry as a whole. E-business networks may therefore be considered a valuable source of capabilities, resources and possible Sustainable Competitive Advantages (SCAs). 
Many topics in strategy research have been linked to aiding in the process of creating and maintaining an SCA, including the phenomenon of business networks. The phenomenon of e-business networking in order to create sustainable competitive advantages is widely acknowledged. Nevertheless, as mentioned before, the complexity involved in such integration often exceeds that found in typical pre-e-business firms and therefore, unless certain factors are taken into account throughout the collaboration, the network will run into problems and disagreements. This may ultimately jeopardise any future cooperation and subsequently damage the individual partner's reputation and customer satisfaction. Those factors that lead to a strong and profitable network are often referred to as critical success factors. Digman (1990) defines critical success factors as the areas or functions where things must go right to ensure successful competitive performance for an organisation.

Many authors have identified critical factors in networking relationship management; however, research has shown that there are few studies that focus solely on e-business networks. Furthermore the few existing studies only provide a limited number of critical success factors and no comprehensive overview can be found. Therefore, this paper attempts to identify and discuss such factors relevant to e-business collaborations, through the study of various secondary data (mainly case studies and articles). The findings of these studies identified 18 factors that have a direct impact on successful e-business networking. The 18 factors are Leadership, Goals and objectives, Planning and coordination, Risk management, Resources, Trust and confidence, Communication, Relationship development, Cultural adaptation, Security, Technological infrastructure, Operational flexibility, Contractual agreements, Organisational proximity, Customer focus, Win-Win solutions, Core competencies, and Mutual value creation. These critical success factors, if integrated under specific categories, could provide a focus and a framework for further discussion and critical evaluation.

\section{Critical literature review}

Several different factor categorisations have been found in literature. Two of the most significant examples are by Eid et al. (2002) and Bruck (2003). Eid et al. (2002) categorised critical success factors for Business-to-business (B2B) international internet marketing into five groups: marketing-strategy-related factors, website-related factors, global-related factors, internal-related factors, and external-related factors. Bruck (2003), suggested that in his experience with clients of many types, working together and working online, there are three major categories of success factors: people factors, process factors and technology factors. However, both recommended categorisations fail to focus on e-business-related factors that are directly relevant to the complexity of networking and the general goal of SCA. Taking these weaknesses into account, the authors therefore suggest that the 18 factors for successful e-business networking can be put under four distinct groups - strategic network performance, network design, network marketing and network value delivery - which are discussed in the following paragraphs. 


\section{Strategic network performance}

Strategic-network-performance-related factors can be seen as the most important, as networks that are strategically guided are often successful, fast growing, innovative and leading edge (Hagedoorn and Schakenraad, 1994). Crowley et al. (2002) of the consultancy firm Accenture link performance management to a human body, where the brain represents the company's strategy, the skeleton its structure, the muscles its capabilities and the nervous system, in effect, the performance management framework. The authors argue that strategic-network-performance-related factors enable the network partners to link, measure, monitor and coordinate business processes more effectively and efficiently in order to create long-term bottom-line SCAs. Drawing on this definition, five critical success factors can be categorised as strategic network performance related: leadership, goals and objectives, planning and coordination, risk management and, finally, resources.

\subsection{Leadership}

Key to successful business networking is significant leadership involvement in the security and performance policy discussion early on (Sevcik and Johnston-Turner, 2002). This is also identified by the European IMP study, who takes it even a step further and suggests that the building of managerial contacts and learning about each other's needs and capabilities imply strong commitments, which are likely to contribute to the mutuality of the relationship (Blankenburg et al., 1999).

Bremer (1996) and Chaffey et al. (2000) all note that top management's support and commitment is one of the keys to collaboration with network partners and that top management commitment to the business network helps to promote implementation across the company. The involvement of functional and territorial heads within the organisation moreover ensures the involvement of the 'key power brokers', who carry weight in getting things done, as managers and staff will take their cue from senior levels (Chan and Swatman, 2000).

\subsection{Goals and objectives}

According to Lynch (2000), the objectives and goals state more precisely than a mission statement what is to be achieved and when the results are to be accomplished. Specific goals of subordinate units may change in the heat of campaigns or competition, but the overriding, so-called strategic goals and objectives must remain clear enough to provide continuity and cohesion for tactical choices during the time horizon of the strategy (Mintzberg et al., 1998).

Setting clear strategic goals and objectives is pointed out by Chaffey et al . (2000) as being one of the critical success factors for e-business networking. This view is shared by Naude and Holland (1996) and Honeycutt et al. (1998), who all provide case study examples that show the importance of clear strategic goal setting. Similarly, a report on collaborative e-business by the Australian Government's Information Technology Online (ITOL) programme shows that the starting point for e-business networking is not about a particular technology solution, but rather about agreeing on a set of common goals and 
objectives (ITOL, 2002). Tiwana and McLean (2001) appear to support this, as they believe that e-businesses executing collaborative activities must be able to integrate their unique competencies towards a shared goal.

\subsection{Planning and coordination}

Engaging in an e-business network is a major business transformation process and reaping the benefits is an evolutionary process. Therefore a dedicated planning phase is a wise investment in a project's success strategy, despite the extreme resource intensity of such a preparation phase. A formal planning system allows the development and implementation of the strategies related to the mission and objectives of an organisation. Mitchell (2000) suggests that successful network management strategy depends to a large extent on planning. Central to Mitchell's (2000) argument for the planning stage is the need to identify the precise customer response that is to be made together with the joint capabilities required for success.

Other studies show that the lack of adequate groundwork could not only result in delays and failure to deliver value, but also would eventually jeopardise the relationship with partners (ITOL, 2002). A well-developed networking plan and associated budget will also be helpful in assessing resource base should the project need to swerve from its original plan. The network plan should identify distinct project phases and stages, with each phase being mandatory before the next one is to set in.

\subsection{Risk management}

Research of literature has shown that one of the critical strategic decisions taken by some organisations has been to build up the function of risk management. Ritchie and Marshall (1993) suggest that risk management may be seen as a part of the organisation's general financial planning and control activity. However, there are also technological overtones to the activity in that losses may flow from the processes undertaken by the organisation. Bocij et al. (2003, p.719) therefore suggest that "risk management aims to anticipate the future risks of an information systems project and to put in place measures to counter or eliminate these risks".

The Little (2001) survey identified risk involved as one of the critical success factors for successful collaboration. 'New' economy companies do rank this element higher than 'old' economy companies, mainly due to the technology- and know-how-driven nature of their business. In an e-business network the retention, exploitation and sharing of knowledge will deliver sustainable competitive advantages (Lynch, 2000).

\subsection{Resources}

Chaffey et al. (2000) identified resources as one of the success factors which play an important role in facilitating network implementations. Similarly, Lynch's (2000) resource-based view stresses the importance of resources in delivering the competitive advantages of the network. Undoubtedly, large firms still enjoy competitive advantage because of larger resources and more visibility among prospective customers worldwide. Within an e-business network it is important that these resources are allocated towards each partner. The process of allocating the resources of the organisation 
selectively between competing strategies according to their merit is considered by many authors to be a critical factor in the success of an e-business network (Lynch, 2000; Bocij et al., 2003).

\section{Proposition 1 Drawing on the above-presented literature, the authors propose that network-performance-related factors have a critical influence on the success of e-business networks.}

\section{Network marketing}

The second category consists of factors related to network marketing. Originating from Scandinavian research, network marketing accepts the influence of a web of interdependencies between firms. Relationship marketing has a clear focus on a business managing the relationship cycle with its customers, while network marketing recognises interdependencies and a wider range of stakeholders (Mattson, 1997). Network marketing is only prescriptive in emphasising the importance of networks in understanding how firms behave rather than telling of a winning strategy (Kotler et al., 2001). The authors suggest that network-marketing-related factors should focus on the interactive, continuous and multi-personal communication between organisations, suppliers and customers at many levels and of various intensity, establishing links between organisations through strong reciprocal relationships. According to this definition four network marketing related critical success factors have been grouped together: relationship development, communication, confidence and trust, and cultural adaptability.

\subsection{Relationship development}

Chan and Swatman (2000) provided another dimension to collaboration when they mentioned trading partners' relationships as the critical issue that faces a company's attempt to achieve its objectives within an e-business network. In literature, several tools for the development of internal and external relationships are discussed. Two of the most common are relationship marketing and public relations. Dierkes et al. (2001) appear to support this, by arguing that if the partners take the time and trouble to establish a close and personal relationship, their efforts promote a successful collaboration. Other authors add that value added in a relationship, or by a relationship, may give it a competitive edge (Ramirez, 1999), as a close relationship with a customer, supplier and even with a competitor can represent a strategic asset (Johnson, 1999).

A general theoretical model proposed by Hoffman (2000) shows how healthy dyadic relationships within an e-business network environment affect the creation of SCAs in four steps. First, the network identity is identified as an antecedent of trust, followed by the proposal that communication is an antecedent of both trust and organisational learning. Third, commitment is seen as the result of both trust and organisational learning, and in the final step trust and commitment are believed to result in SCAs for the network. 


\subsection{Communication}

The flow of communication is vital to the success of e-business networking, because it binds all those partners involved in achieving the goals of the network (Christie and Levary, 1998). Complete collaboration based on open interactive communication is crucial; especially as the network partners might be rivals or competitors in other business areas. According to Ibrahim (2003), the use of 'modern real-time communication technologies' will enhance the power of information and will contribute to the success of the e-business network.

Literature distinguishes two main types of communication, informal and formal. Informal communication describes information that is transmitted by informal means such as casual conversations between members of staff. This information is often less structured and less detailed than information transmitted by formal communication. Formal communication presents information in a structured and consistent manner (Bocij et al., 2003). Such information is normally created for a specific purpose, making it likely to be more comprehensive, accurate and relevant than information transmitted using informal communication (Bocij et al., 2003).

\subsection{Trust and confidence}

Networking makes e-businesses far more reliant on each other and requires more trust than ever before (Walters and Buchanan, 2001). Trust between networking partners has therefore been highlighted by many authors as one of the key factors having a fundamental impact on the success of collaborative relationships. Christie and Levary (1998) identified trust as an essential factor in successful e-business networking. Each and every partner must have total trust in each other's ability to contribute to the value creation of the network.

Zari (2001) agreed that trust and confidence between collaborating partners is a critical factor for e-business networking success. Ring and Van de Ven (1992) suggested that trust primarily evolves on the basis that the business partner will fulfil its commitments and that the relationship is equitable. Furthermore, the development of trust implies free exchange of information.

Several authors have identified that geographic dispersion of partners in an e-business network can introduce challenges to building trust without face-to-face interaction (Jarvenpaa et al., 1998). Ratnasingham (1998) agreed that trust is more important in the virtual world than in the real world. In the anonymous electronic environment, achieving trust at the beginning of a relationship is more difficult than in the traditional business world, because the company has much less information available to assess the trustworthiness of its partners. However, as identified by Cassell and Bickmore (2000), a degree of trust is needed in order to engage in any form of cooperation, especially one as complex as a network.

\subsection{Cultural adaptability}

Chan and Swatman (2000) point out the criticality of cultural awareness in a networking environment. In the case of an e-business network, every partner has his own cultural web consisting of factors that can be used to characterise the culture of the organisation. Usually these factors are summarised as stories, symbols, power structures, 
organisational structure, control systems, routines and rituals (Lynch, 2000). It is therefore critical for any e-business engaging in networking that it create an understanding and willingness to adapt to the external and internal culture of its network partners.

Chan and Swatman (2000) suggest that the culture of different countries must be taken into account when building e-business networks. The internal or organisational culture on the other hand consists of the style and learned ways that govern and shape the organisation's people relationships (Lynch, 2000); therefore an organisation must understand and conform to the new values, management processes and communication styles that are being created by the network. It is important for the e-business network as a whole to develop a strong cultural identity, which provides a framework in which members can operate confidently.

Proposition 2 From the extensive amount of literature gathered, the authors propose that network-marketing-related factors have a critical influence on the success of e-business networks.

\section{Network design}

The third category consists of factors related to network design. When companies collaborate with others, more precise understanding is required on their information patterns and flow, how they need to manage that and how to capture the new information requirements. Systems are not always flexible enough to cope with change, especially with the radical changes that collaborative networking incorporates (Abbosh and Qazilbash, 2002). Therefore it is essential for e-business networks to re-design their infrastructure and use data more effectively. Network design is potentially of high value, both in terms of its expense and importance to the company. The authors argue that network design related factors facilitate the e-business network with flexible operational facilities, enabling the networking partners to cooperate within an infrastructural framework. Keeping this definition in mind, the following five critical success factors for e-business networking have been allocated towards network design: technological infrastructure, security, contractual agreements, operational flexibility and organisational proximity.

\subsection{Technological infrastructure}

Researchers such as Naude and Holland (1996) consider an adequate technological infrastructure as a critical success factor for e-business networking implementations. Likewise Walters and Buchanan (2001) also point out the importance of technology in e-business networks. Similarly, Gogan (1997) cites that selecting the appropriate technological infrastructure is a key factor for e-business networking.

In order to determine the most appropriate technological infrastructure comprising hardware, networks and software applications, an e-business network must follow a suitable information technology strategy (Bocij et al., 2003). Bremer (1996) argues that for such a strategy to become successful, technical resources and security technology are critical. 


\subsection{Security}

Each interaction between network partners is also a potential security risk, as today's business partner may be tomorrow's competitor. Therefore, Christie and Levary (1998) suggest that security and privacy measures within the network are a critical success factor to the overall value creation of the network. According to Ratnasingham (1998), the most important area affecting the success of e-business networking is network system and application component security. Likewise, Hack (2001) identifies privacy and security features as important to successful collaboration.

However, even though security is essential for a successful e-business network, Sevcik and Johnston-Turner (2002) argue that too much security can scare away business partners, as total restriction would defeat the purpose of building a cooperative e-business network. The most critical network security trade-offs relate to business operations, financial transactions and information.

\subsection{Contractual agreements}

According to Hack (2001), defining the collaboration is the underpinning of successful e-business network efforts, which asks for a common and accepted legal agreement. Correspondingly, Warkentin et al. (2001) identifies that a critical success factor determining the adaptation of such new economy networks will be the alignment of proper economic incentives and revenue sharing agreements for all the players involved. Bocij et al. (2003) on the other hand focuses on service level agreements, which set the contractual specification of service standards each partner within the network must meet.

The ITOL experience has shown the importance of clear written agreements delineating each partner's roles and responsibilities. Written agreements are the most effective way of locking in commitment and keeping any collaborative project focused and on track. E-business networks that have clearly established 'who' does 'what' have the greatest chance of succeeding (ITOL, 2002).

\subsection{Operational flexibility}

Damanpour (2001) identified that collaboration is never stagnant and being flexible when collaborating is a critical factor for successful networking. Networks are constantly changing and can be used for continuous improvements (Boe, 2001) In terms of operations strategy, the development of networks requires flexibility and responsiveness, and will often necessitate the need for more than one strategy that is customised by a particular customer or product group (Lowson and Burgess, 2003). Such strategies that ensure reserved capabilities, planned manoeuvrability and repositioning allow for the use of minimum resources while keeping opponents at a relative disadvantage (Mintzberg et al., 1998).

This can be achieved by implementing electronic systems that generate immediate knowledge about internal functions and processes, about customers and markets, but also about the strategic partners within the network (Warkentin et al., 2001). However, Warkentin et al. (2001) state that only new e-business models could facilitate the development and adaptation of e-business networks. 


\subsection{Organisational proximity}

Organisational proximity is a much more important critical success factor for successful e-business networks than geographic proximity. According to Rallet and Torre (1998), organisational proximity is an effective enabler of strategic collaboration and coordination. The term 'organisational proximity' is used to describe the nearness of the organisational cultures of the individual partners. Every organisation has its own unique culture and most large organisations are likely to be something of a mix of cultures with a collection of traditions, values, policies, beliefs and attitudes that constitute a pervasive context for everything done and thought in an organisation (Mclean and Marshall, 1993). Organisational proximity to their partners therefore supports any form of collaboration. This proximity reinforces the sense of collectiveness on which successful networking thrives (Dierkes et al., 2001).

\section{Proposition 3 Based on the researched literature, the authors propose that network-design-related factors have a critical influence on the success of e-business networks.}

\section{Network value delivery}

In its search for competitive advantages, the firm needs to look beyond its own value chain, into the value chain of its suppliers, distributors and, ultimately, competitors (Kotler et al., 2001). As companies engage in networks, they no longer strive for individual competitive advantages, but rather aspire to improve the performance of the entire network value delivery system. A network value delivery system is made up of the value chains of the company and its networking partners, who cooperate in order to deliver increased value to customers. For network utilities, keeping assets healthy and operating efficiently is a core activity in order to create shareholder value. Asset management is all about optimising all inputs to generate the right combination of maximised outputs from a company's system (Abbosh and Qazilbash, 2002). In the case of a network, asset management is focused on the optimisation of shared inputs in order to optimise mutual output value for all network partners, taking into account service quality, costs to run, level of risk, etc. The authors' view is that network-value-deliveryrelated factors should focus on the development of approaches to input and output relationships, balancing operational, technical and commercial aspects in order to release scale synergies over and above that which would be possible with individual companies. This fourth category entails four critical success factors for e-business networking: customer focus, core competencies, win-win solutions and mutual value creation.

\subsection{Customer focus}

As identified by Christie and Levary (1998), focus on customer needs is one of the critical success factors for e-business networks. Herbig and Hale (1997) also emphasise that customer needs must be identified. Similarly, Damanpour (2001) shows the importance of meeting client demand as necessary in fulfilling obligations in e-business networking. Networks that are highly focused on customer satisfaction and manage to forecast and meet their customer needs will in a timely manner be successful in creating 
valuable SCAs. However, Hack (2001) points out that customer needs are easily forgotten in the quest for implementing networking solutions. Therefore an e-business network should follow a customer-driven strategy, where every function is directed towards customer satisfaction.

In today's business markets, Customer Relationship Management (CRM) plays an important role in achieving customer satisfaction. Essentially, customer relationship management involves a company forming long-term business relationships with its customers for mutual benefits. The aim of CRM is to improve customer service without harming company profitability. Therefore, Kalakota and Whinston (1997) suggest that the operational excellence model that delivers high customer satisfaction is built on an e-business infrastructure that has four main characteristics: it is easy to use, has rich functionality, is reliable and delivers integrated performance.

\subsection{Core competencies}

Choosing the right partner with the right core competencies outlines the fundament of an e-business network and according to Christie and Levary (1998) represents the most important factor in success or failure. Walters and Buchanan (2001) support this view and point out that only if each partner brings its core competence to the effort can network excellence be achieved. Both Jobber (2004), and Mintzberg et al. (1998) provide similar definitions of the term 'core competencies', stating that core competencies are the principal distinctive capabilities possessed by a company - what it is really good at. Together, these competencies form the key resources of the e-business network that assist it in being distinct from its competitors.

For successful e-business networking it is important that its members share their core competencies and operate without borders (Walters and Buchanan, 2001). More cooperation between competitors, suppliers and customers makes it harder to determine where one company ends and another begins. This allows each partner to benefit from its partners' core competencies and will contribute to the success of the network as a whole. Collaborative competencies might be used later in design and management of other collaborations (Lyles, 1988).

\subsection{Win-win solutions}

Successful collaboration and networking in e-business is, from the start, focused on win-win outcomes far beyond shifting costs. Creating a win-win situation for all involved parties is the primary obstacle, if the long-term benefits of the collaboration are to outweigh any required investment (Hack, 2001). Christie and Levary (1998) suggest that the success of a network depends on the degree of collaboration and cooperation between the participating partners and as such the goals of the partnership should result in a win-win outcome in the interest of all involved partners. Similarly, Buechel et al. (1998) point out that mutual long-term benefit can only be achieved through a win-win approach, as mutuality of interest replaces zero-sum tactics with win-win solutions. 


\subsection{Mutual value creation}

An empirical analysis of the European International Marketing and Purchasing (IMP) project demonstrates a causal chain from business network connection through mutual commitment and mutual dependence to mutual value creation in the relationship. The result shows that mutuality in e-business network relationships is a critical factor in developing SCAs (Blankenburg et al., 1999).

As pointed out by Zajac and Olsen (1993), a central theme of the research in this field concerns the 'interdependence of exchange partners seeking gain'. The emerging mutual commitment of the firms to the relationship allows them to develop a mutual dependence associated with the coordination of interdependent activities in a way that increases the level of joint productivity (Zajac and Olsen, 1993). Thus, the process gradually transforms a dependence relation into a relation between two or more e-businesses with mutual interest in a value-creating relationship (Wilson, 1995). Barney (1996) describes relationship value creation as the effect of the relationship on the joint economic performance of the partner firms involved.

Proposition 4 Drawing on the above-presented literature, the authors propose that factors related to network value delivery have a critical influence on the success of collaborative e-business networks.

Based on the above-reviewed literature and the set propositions, a conceptual model for e-business networking will be discussed in the following section.

\section{Development of the conceptual model}

The idea behind developing a model of critical success factors by primarily focusing on e-business networking is that any e-business engaging in a network should know which areas or functions to concentrate on and deploy their valuable resources. An appropriate strategy would ensure successful competitive performance for the individual organisation or network as a whole. This model does not offer solutions to organisational problems, but rather ways to reduce the complexities and uncertainties involved. Figure 1 shows the graphical presentation of the strategic model for successful e-business networking, followed by a brief description.

The presented conceptual model for successful e-business networking as shown in Figure 1 gives an overview of all critical success factors identified through literature review and integrates them in four main groups. The model consists of three layers, surrounding the core or purpose of this model, which can be defined as 'successful e-business networking', and follows an 'inside-out' approach. In order to achieve a profitable collaboration in e-business, the authors suggest that there are 18 critical aspects of e-business that should be considered by any e-business collaborating in the form of a network. 
Figure 1 The conceptual strategic model for successful e-business networking

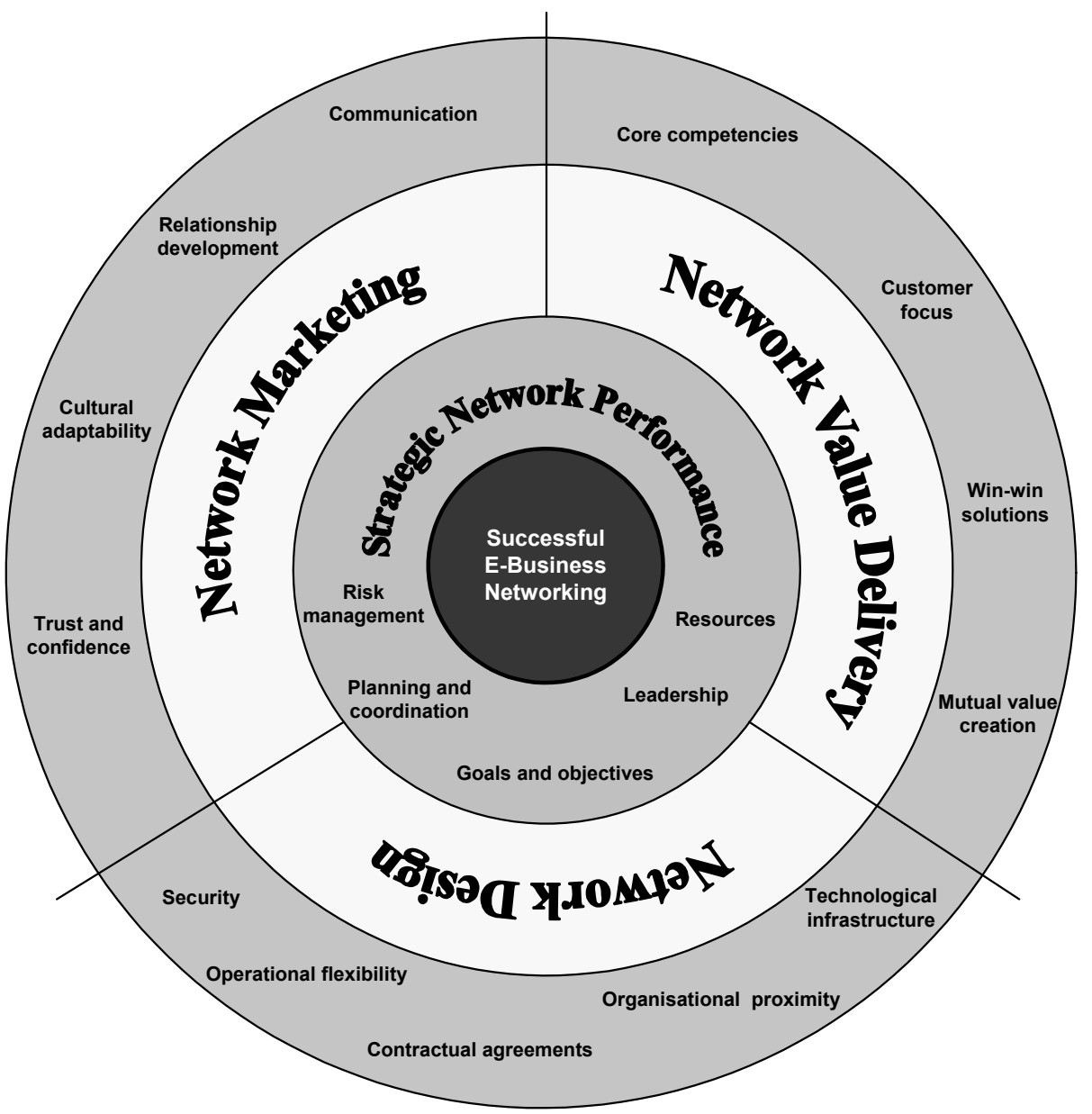

The first layer surrounding the core of this model consists of strategic networkperformance-related factors. Due to the strategic nature of the five critical success factors allocated towards this category, the authors argue that they should be addressed first and they have therefore been moved one level up from the other categories. It is suggested that these factors have to be 'right' before any of the other critical success factors can exist or have an influence on the overall success of any e-business network. Factors such as leadership and risk management, which are related to strategic network performance, are in this model considered to be absolutely crucial to the overall level of network success.

The next layer encircling the core of the model is divided into three equal parts and shows the other three categories of critical success factors: network marketing, network design and network value delivery. After the strategic network-performance-related factors have been addressed, these three categories can be managed subsequently. The outer ring of the model presents the individual critical success factors that have been categorised in these three groups. 
The authors believe that the strength of this model is the concept of successful e-business networking through the identification of critical success factors. The conceptual model developed through literature review provides a broad overview of factors related to e-business networking.

In order to assess the relative importance of the critical success factors incorporated in the conceptual model for successful e-business networking, a pilot study is conducted. The findings of the pilot study are discussed in the following section.

\section{Research methodology}

The pilot study undertaken in this paper aims to support the criticality of the success factors presented based on the reviewed literature. The online questionnaire was advertised on the internet and respondents were invited to access a website and to fill in an online survey. This research is concerned with the very specialised and new topic of e-business networking. It is therefore important that an accurate list of all the cases from which a sample can be drawn is compiled. A so-called 'sampling frame' for this particular study was not found in literature and was put together by the researchers. According to Saunders et al. (2000), it is important to ensure that the sampling frame is unbiased, current and accurate. In order to do this, two criteria were set for the target group. The first criterion was that all respondents had to be employed by an e-business or had experience working for an e-business in the past. The second criterion was that they were currently working in a managerial position within their company. Only if the respondent could answer 'yes' to both questions, would he/she be asked to continue and answer the questionnaire. This guaranteed the researchers high-quality data, but also meant that the sample target group was very limited. However, the researchers were reluctant to compromise the quality of the primary data collection and therefore accepted the fact that the eventual number of responses might be limited. The online survey resulted in a total number of 57 completed responses obtained within one month from 15 different countries and companies. Although a higher number of responses would have been ideal, the researchers believe 57 to be a reasonable number, considering the quality of responses received. The criteria to be fulfilled by the respondents guaranteed that the researchers were provided with high-quality data from respondents with inside knowledge of e-business. Most of the responses came from companies which are based in Germany, the USA and The Netherlands, and are active mainly in 'IT' and 'Service industries'. It is interesting to see that over half the companies (30 out of 57) have five to ten years' experience in e-business, whereas only five of them have more than ten years' experience. Furthermore, approximately half the companies have experience with networking in e-business, whereas the other half do not have such experience yet.

The participants in the questionnaire provided numerical scores that expressed their opinion on the level of importance of each critical success factor and its effect on achieving successful e-business networking. 


\section{Importance index for critical success factors}

The authors decided to calculate the weighted average for each critical success factor and then divided this by the upper scale of the measurement. This results in an importance index. Therefore the level of importance of critical success factors within their category was calculated using the following formula:

$$
\text { Importance Index }=\sum(\mathrm{aX}) * 100 / \mathrm{M}
$$

where:

$\mathrm{a}=$ constant that expresses the weighting given to each response, scaling from 0 (no importance at all), 1 (not important) to M (extremely important); where $\mathrm{M}$ is the number of critical success factors within each category.

$\mathrm{X}=\mathrm{n} / \mathrm{N}$, where $\mathrm{n}=$ the frequency of the responses and $\mathrm{N}=$ the total number of responses.

The findings of the importance index are presented in Table 1. The factors have been presented in order of importance, starting with the most important factor, followed by the next important factor and so on.

Table 1 Importance index of critical success factors for e-business networking

\begin{tabular}{lc}
\hline Critical success factors in their respective groups & Importance index (max. 100) \\
\hline Strategic network performance & 77.5 \\
Leadership & 65.9 \\
Goals and objectives & 62.7 \\
Planning and coordination & 49.1 \\
Risk management & 33.6 \\
Resources & \\
Network marketing & 67.6 \\
Trust and confidence & 65.4 \\
Communication & 60.8 \\
Relationship development & 40.1 \\
Cultural adaptation & \\
Network design & 71.9 \\
Security & 61.9 \\
Technological infrastructure & 56.9 \\
Operational flexibility & 54.6 \\
Contractual agreements & 36.3 \\
Organisational proximity & \\
Network value delivery & 76.9 \\
Customer focus & 54.1 \\
Win-win solutions & 52.3 \\
Core competencies & 51.7 \\
Mutual value creation & \\
\hline
\end{tabular}




\subsection{Strategic-network-performance-related critical success factors}

The result of the importance index calculations, as presented in Table 1, show that leadership achieved the highest level of importance with a score of 77.5 , followed by goals and objectives with 65.9 and planning and coordination with an importance index of 62.7. Risk management and resources ranked lowest, with scores of 49.1 and 33.6. These findings echoed the findings of the literature review, which identified leadership and common goals and objectives as essential to e-business networking.

Furthermore the findings of the above-presented importance index are also supported by the Little (2001) survey, which rated leadership with an importance index of 79 and goals and objectives with 87 .

\subsection{Network-marketing-related critical success factors}

Except for cultural adaptation (importance index of 40.1), all the critical success factors were rated with an average importance of more than 60. Trust and confidence was rated most important with a level of importance of 67.58 , followed by communication with 65.4. The Little (2001) survey confirms the importance of regular communication for networking. The respondents in his survey rated regular communication with an average importance index of 90. This is much higher than the importance index score of communication found in this research. However, in the Arthur D. Little survey communication and trust were treated as one success factor, whereas in this research trust and confidence was identified as a separate factor for successful e-business networking.

The importance index of relationship development (60.8) supports the view of several authors (Boe, 2001; Bruck, 2003; Sevcik and Johnston-Turner, 2002) that getting partners to network successfully is more of a people problem than a technology problem.

\subsection{Network-design-related critical success factors}

The data analysis demonstrated that security was clearly seen as the most important factor within this category, as identified by its score of 71.9. This reflects the rising concerns for security of anyone participating in online business. Overall this is the third highest score achieved by any individual critical success factor in this analysis. On the other hand, the lowest overall score can also be found in this category, as organisational proximity was only rated with an importance index of 36.3 (Table 1).

Furthermore, the importance index shows a 61.9 score for technological infrastructure, an importance index of 56.9 for operational flexibility and a 54.61 score for contractual agreements. However, the importance of contractual agreements can still be considered to be high, as indicated by the score.

\subsection{Network-value-delivery-related critical success factors}

The importance index shows that the respondents certainly perceive all the success factors as critical. Customer focus was regarded as highly important and even achieved the second-highest score of all critical success factors, as indicated by the importance index of 76.9 (Table 1). Furthermore, the importance index shows that win-win solutions, core competencies and mutual value creation were given a more or less same level of importance, with importance indexes of 54.1, 52.3 and 51.7 respectively. 
The relatively high scores in the importance index for customer focus in this category justifies Christie and Levary's (1998) views, as they suggest that focus on customer needs is one of the critical success factors for e-business networks.

\section{Suggestions for further development of the conceptual strategic model for e-business networking}

The authors suggested the following three critical criteria that can be applied when excluding a variable from a specific category to develop further the strategic model for e-business networking:

1 The four distinct categories strategic network performance, network design, network marketing and network value delivery - can be considered as dependent factors and the variables within each distinct factor as independent variables. Independent variables together in each category should explain the variation in the dependent factor. The variable has to be excluded in the stepwise multiple regression analysis.

2 The importance index of the variable within a specific category has to be considerably lower than $50 \%$.

3 Statistical test between the two lowest variables (the lowest having an importance index of considerably less than 50\%) within each category should reveal a significant difference in the mean score between them.

Any variable to be excluded from the final model has to meet all these three critical criteria. These three criteria have been carefully developed in order to ensure that any variable included in the final model has gone through the stringent process of elimination.

In the present study, results obtained from a pilot test based on a sample size of 57 indicated that the above-mentioned criteria are effective in developing a strategic model for e-business networking. However, these criteria should be tested using a large representative sample before making any general conclusion on the final structure of the model for e-business networking.

\section{Conclusion}

A review of the literature on e-business networking identified certain key factors that were considered to be critical for successful e-business networking. Based on the gathered literature and the understanding of the key factors for e-business networking, the authors developed a conceptual model for successful e-business networking. The conceptual model consists of four main categories: strategic network performance, network design, network marketing and network value delivery. The authors developed a definition for each of these categories. Based on these definitions, a total number of 18 critical success factors for successful e-business networking were integrated within the four categories. This categorisation of the critical success factors was considered to be appropriate in order to ensure the practical applicability of the model. A model for successful e-business networking consisting of 18 variables would have been difficult to 
implement in practice due to its complexity and operational constraints. Whereas, a categorisation of the critical success factors provides a more structured overview of the key aspects to be addressed by any e-business network in order to be successful.

In order to support the conceptual model for successful e-business networking a pilot study was conducted in the form of an online survey. The importance indexes showed that all identified success factors were given a certain level of importance by the respondents and no critical success factor was given zero importance. However, on examination of the importance index results it was found that some of the critical success factors, such as leadership, security and customer focus (importance index of more than 70) were considered much more important than others. In addition, only four variables have an importance index of lower than 50; risk management, resources, organisational proximity and cultural adaptability.

The advantages of e-business networking could potentially be enormous, however literature also calls for caution, in that network structures and operations are very complex. Therefore, the authors argue that this model for e-business networking could be of great value to any e-business engaging in network collaborations. However, the conceptual model needs to be tested using a large sample, collecting data through a longitudinal study.

This research developed a conceptual model for successful e-business networking in order to be competitive in the new economy. This unfolded the following potential areas for future research:

- Key performance indicators for each critical success factor could be developed in order to measure and monitor the strategic objectives against its delivery on a continuous and regular basis.

- Processes for each critical success factor could be designed in order to optimise their functions on operations, which could lead to the development of a lean e-business network.

\section{References}

Abbosh, O. and Qazilbash, K. (2002) 'Asset management - network delivery', Utility Week (online), December, http://www.accenture.com/xd/xd.asp?it=enweb\&xd=industries\% 5Cresources\%5Cutilities\%5Cutil_asset.xml (Accessed 28 January 2004).

Barney, J.B. (1996) Gaining and Sustaining Competitive Advantage, Reading, MA: Addison-Wesley.

Blankenburg Holm, D., Eriksson, K. and Johanson, J. (1999) 'Creating value through mutual commitment to business network relationships', Strategic Management Journal (online), Chichester, Vol. 20, No. 5, p.467.

Bocij, P., Chaffey, D., Greasley, A. and Hickie, S. (2003) Business Information Systems - Technology, Development and Management for e-Business, 2nd ed., UK: Prentice Hall.

Boe, E. (2001) 'The future of collaborative e-business: building a blueprint for eCollaborative opportunities', Industrial Marketing Management, Vol. 15, No. 2, p.9.

Bremer, M. (1996) 'Productivity, policy and internet training issues', The Internet Strategy Handbook: Lessons from the New Frontiers in Business, Boston, MA: Harvard Business School Press.

Bruck, B. (2003) 'How companies collaborate sharing online', A Collaboration Architects, White Paper, 14 January, pp.1-25. 
Buechel, B., Prange, C., Probst, G. and Ruling, C.C. (1998) International Joint Venture Management - Learning to Cooperate and Cooperating to Learn, Singapore: Wiley.

Cassell, J. and Bickmore, T. (2000) 'External manifestations of trustworthiness in the interface', Communications of the ACM, Vol. 43, No. 12, pp.50-56.

Castells, M. (2000) The Rise of the Network Society, 2nd ed., Oxford: Blackwell Publishers.

Chaffey, D., Mayer, R., Johnston, K. and Ellis-Chadwick, F. (2000) Internet Marketing, London: Prentice-Hall.

Chan, C. and Swatman, P.M.C. (2000) 'From EDI to internet commerce: the BHL Steel experiences', Internet Research: Electronic Networking Applications and Policy, Vol. 10, No. 1, pp.77-82.

Christie, M.J. and Levary, R. (1998) 'Virtual corporations: recipe for success', Industrial Management, July-August, Vol. 40, No. 4, pp.7-11.

Cook, K.S. and Emerson, R.M. (1984) 'Exchange networks and the analysis of complex organisations', Research in the Sociology of Organisations, Greenwich, CT: JAI Press, Vol. 3, pp.1-30.

Crowley, J., Gibson, F.E. and Heyns, H.N. (2002) 'New age performance management - nervous systems', Utility Week, November 2002, http://www.accenture.com/xd/xd.asp?it=enweb\&xd =industries\resourceslutilitieslutil_perform.xml.

Damanpour, F. (2001) 'E-business e-commerce evolution: perspective and strategy', Managerial Finance, Vol. 27, No. 7, pp.17-33.

Dierkes, M., Berthoin Antal, A., Child, J. and Nonaka, I. (2001) Handbook of Organisational Learning and Knowledge, 1st ed., New York: Oxford University Press Inc.

Digman, L.A. (1990) Strategic Management: Concepts, Decisions, Cases, 2nd ed., Homewood, IL: Irwin.

Eid, R., Trueman, M. and Ahmed, A.M. (2002) 'A cross-industry review of B2B critical success factors', Journal of Electronic Networking Applications and Policy, Vol. 12, No. 2, pp.110-123.

Gogan, J.L. (1997) 'The web's impact on selling techniques: historical perspective and early observations', International Journal of Electronic Commerce, Vol. 1, No. 2, pp.89-108.

Hack, S. (2001) 'The future of collaborative e-business: building a blueprint for eCollaborative Opportunities', Introduction, Vol. 15, No. 2, p.3.

Hagedoorn, J. and Schakenraad, J. (1994) 'The effect of strategic technology alliances on company performance', Strategic Management Journal, Vol. 15, pp.291-309.

Herbig, P. and Hale, B. (1997) 'Internet: the marketing challenge of the twentieth century', Internet Research Electronic: Network Application and Policy, Vol. 7, No. 2, pp.95-100.

Hinterhuber, H.H. and Hirsch, A. (1998) 'Starting up a strategic network', Thunderbird International Business Review, New York, May-June, Vol. 40, No. 3, pp.185-208.

Hoffman, N.P. (2000) 'An examination of the sustainable competitive advantage: concept: past, present and future', Academy of Marketing Science Review (online), Vancouver, Vol. 2000, p.1.

Honeycutt, E.D., Flaherty, T.B. and Benassi, K. (1998) 'Marketing industrial products on the internet', Industrial Marketing Management, Vol. 27, No. 1, pp.63-72.

Ibrahim, N. (2003) The Virtual Corporation - Virtual Success or Failure, USA: Akauntan.

Information Technology Online (ITOL) (2002) Guide to Successful eBusiness Collaboration, http://www.noie.gov.au/itol (accessed on 10 February 2004).

Jarvenpaa, S.L., Knoll, K. and Leidner, D.E. (1998) 'Is anybody out there?: Antecedents of trust in global virtual teams', Journal of Management Information Systems, Vol. 14, No. 4, pp.29-64.

Jobber, D. (2004) Principles and Practice of Marketing, 4th ed., McGraw-Hill, Berkshire. 
Johnson, J.L. (1999) 'Strategic integration in industrial distribution channels: managing the interfirm relationship as a strategic asset', Journal of the Academy of Marketing Sciences, Vol. 27, No. 1, pp.4-18.

Kalakota, R. and Whinston, A. (1997) Electric Commerce: A Managers Guide, Reading, MA: Addison Wesley.

Kotler, P., Armstrong, G., Saunders, J. and Wong, V. (2001) Principles of Marketing, 3rd ed., Pearson Education Limited, Essex.

Koza, M.P. and Lewin, A.Y. (2000) Putting the Sword Back into Alliances - Mastering Strategy, London: Financial Times/Prentice-Hall.

Little, A.D. (2001) 'Partnering: challenges for the old and new economy', Facts-AssessmentsRecommendations Based on a Global Arthur D. Little Survey, London.

Lowson, R.H. and Burgess, N.J. (2003) 'The building blocks of an operations strategy for e-business', The TQM Magazine, Vol. 15, No. 3, pp.152-163.

Lyles, M.A. (1988) 'Learning among joint venture-sophisticated firms', in F. Contractor and P. Lorange (Eds.) Cooperative Strategies in International Business, Lexington, MA: Lexington Books, pp.301-316.

Lynch, R. (2000) Corporate Strategy, 2nd ed., UK: Prentice Hall.

Mattson, L.G. (1997) 'Relationship marketing and the markets-as-networks-approach - a comparative analysis of two evolving streams of research', Journal of Marketing Management.

McCullough, S. and Johnston, K. (2001) Why E-business Must Evolve Beyond Market Orientation?, (online), Derby: MCB University Press, http://www.mcbup.com/research _registers.

McLean, A. and Marshall, J. (1993) 'Intervening in cultures', Working Paper, University of Bath, UK.

Mintzberg, H., Quinn, J.B. and Ghoshal, S. (1998) The Strategy Process, Revised European Edition, Europe, UK: Prentice Hall.

Mitchell, W. (2000) 'Alliances: achieving long-term value and short-term goals', Mastering Strategy, London: Financial Times/Prentice-Hall.

Naude, P. and Holland, C. (1996) Business-to-Business Relationships, in Relationship Marketing, Theory and Practice, London: Paul Chapman Publishing.

Rallet, A. and Torre, A. (1998) 'On geography and technology relations in localised innovation networks', in M. Steiner (Ed.) Clusters and Regional Specialisation, London: Pion.

Ramirez, R. (1999) 'Value co-production: intellectual origins and implications for practice and research', Strategic Management Journal, Vol. 20, pp.49-65.

Ratnasingham, P. (1998) 'The importance of trust in e-Commerce', Internet Research: Electronic Networking Applications and Policy, Vol. 8, No. 4, pp.313-321.

Ring, P.S. and Van de Ven, A.H. (1992) 'Structuring cooperative relationships between organisations', Strategic Management Journal, Vol. 13, pp.483-498.

Ritchie, R. and Marshall, D. (1993) Business Risk Management, 1st ed., Oxford: Chapman and Hall.

Rowley, J. (2002) E-Business: Principles and Practice, New York: Palgrave.

Saunders, M., Lewis, P. and Thornhill, A. (2000) Research Methods for Business Students, 2nd ed., London: Financial Times Prentice Hall.

Sevcik, P. and Johnston-Turner, M. (2002) 'Policy-based e-business networks maximize ROI', Business Communications Review (online), Hindsdale, Vol. 32, No. 10, pp.56-59.

Tiwana, A. and McLean, E.R. (2001) 'Towards a theory of architectural knowledge integration capability: a test of an empirical model in e-business project teams', Proceedings of the 9th European Conference on Information Systems, Bled, Slovenia, pp.787-793. 
Vassilopoulou, K., Pouloudi, A., Patronidou, S. and Poulymenakou, A. (2002) E-Business Models: A Proposed Framework, Athens University of Economics and Business, Athens.

Walters, D. and Buchanan, J. (2001) 'The new economy, new opportunities and new structures', Management Decisions, London, Vol. 39, No. 10, pp.818-834.

Warkentin, M., Sugumaran, V. and Bapna, R. (2001) 'E-knowledge networks for inter-organisational collaborative e-business', Logistics Information Management, Vol. 14, Nos. 1-2, pp.149-162.

Wilson, D.T. (1995) 'An integrated model of buyer-seller relationships', Journal of the Academy of Marketing Science, Vol. 23, No. 4, pp.335-345.

Zajac, E.J. and Olsen, C.P. (1993) 'From transaction cost to transaction value analysis: implications for the study of interorganisational strategies', Journal of Management Studies, January, Vol. 30, pp.131-145.

Zari, M. (2001) E-capability: From Transactional to Collaborative Competitiveness, Special Presentation, Bradford School of Management, Bradford University, Bradford. 